\title{
PHARMACEUTICALS AND RELATED COMPOUNDS AS EMERGING POLLUTANTS IN WATER: ANALYTICAL ASPECTS
}

\section{A. NIKOLAOU}

\author{
Department of Marine Sciences, \\ University of the Aegean \\ University Hill, 81100 Mytilene, Lesvos, Greece
}

*to whom all correspondence should be addressed:

Accepted: $10 / 12 / 12$

e-mail: nnikol@aegean.gr

\begin{abstract}
Emerging pollutants are increasingly detected in aqueous environmental samples, with pharmaceuticals and related compounds consisting a large category with many diverse groups, including parent compounds and their metabolites/transformation products. Significant research is performed on this subject worldwide, in order to obtain information regarding their occurrence, fate and health effects. In this effort, development and optimization of highly sensitive and accurate analytical methods for their determination in environmental samples is a necessity, but also a challenge. Advanced analytical methods for emerging pollutants include liquid chromatography (LC) or gas chromatography (GC) followed by tandem mass spectrometric (MS/MS) detection. These methods, combined with a variety of sample preparation procedures, provide the ability to analyze emerging pollutants in the environment in trace levels, and to identify and quantify their oxidation/degradation products. However, there are still many analytical aspects that need improvement and optimization for increasing the accuracy and sensitivity of the methods, in order to be able to fill the gaps of knowledge on the studied compounds.
\end{abstract}

KEYWORDS: Emerging pollutants; environmental analysis; sample preparation; derivatization; GCMS; LC-MS/MS; transformation products.

\section{INTRODUCTION}

The occurrence of non-polar toxic chemical substances in water has been a subject of major scientific interest during the last decades. Particular emphasis has been paid to substances such as polychlorinated biphenyls (PCBs), polycyclic aromatic hydrocarbons (PAHs) and heavy metals. Their determination in water matrices has been widely performed in the framework of monitoring programs, and their concentrations have been regulated in order to safeguard water quality (Hale et al., 2010; Kalantzi and Siskos, 2011; Hadjibiros et al., 2011; Babi et al., 2011; Ekmekyapar et al., 2012; Petreas et al., 2012).

On the other hand, nowadays increasing concern is raised from a large number of "emerging pollutants", in this case mostly polar compounds, that can be easily dissolved in water and transported through the water cycle. The term emerging pollutants describes pollutants currently being released into the environment, without having been regulated yet. The reasons that prevent their regulation are mostly the lack of information regarding their occurrence and toxicity, the lack of appropriate analytical methods for their determination, or both. These compounds derive from human activities such as industry, agriculture, domestic use, wastewater. Special interest also attract their transformation products that can be formed during water and wastewater treatment, as well as due to processes occurring in natural waters such as biodegradation, photodegradation, hydrolysis etc. (Bloutsos and Giannopoulos, 2011; Smeti et al., 2011; Kalantzi and Alcock, 2012; Thomaidis et al., 2012; Siddique et al., 2012). 
Emerging pollutants can be candidates for future regulation, provided that adequate data on their toxicity and potential health effects is obtained. In case of their regulation, they should become subject to routine monitoring, however for many of them there are not yet available analytical methods for their determination in environmental samples. Therefore there is a clear need to develop and optimize such methods, especially for complex environmental samples. This is a difficult task due to the variety of compounds and processes that can interfere during analysis, affecting the precision, accuracy and especially the detection limits of the method. However, since many emerging pollutants and their byproducts are possibly toxic even at trace concentrations, optimizing the analytical methods is a critical issue for the determination of their presence and fate in water (Kostopoulou and Nikolaou, 2008; Karapanagioti et al., 2010; Babi et al., 2011).

Among the major categories of emerging pollutants are pharmaceuticals and illicit drugs, steroid estrogens (hormones and contraceptives) and personal care products. The list of individual compounds belonging to these categories keeps growing, an increasing number of such compounds and their oxidation/degradation products are being detected in trace levels in the environment, as the related techniques for their determination and quantification are being continuously improved (Nikolaou et al., 2007; Fatta et al., 2007; Kostopoulou and Nikolaou, 2008; Fatta-Kassinos et al., 2011).

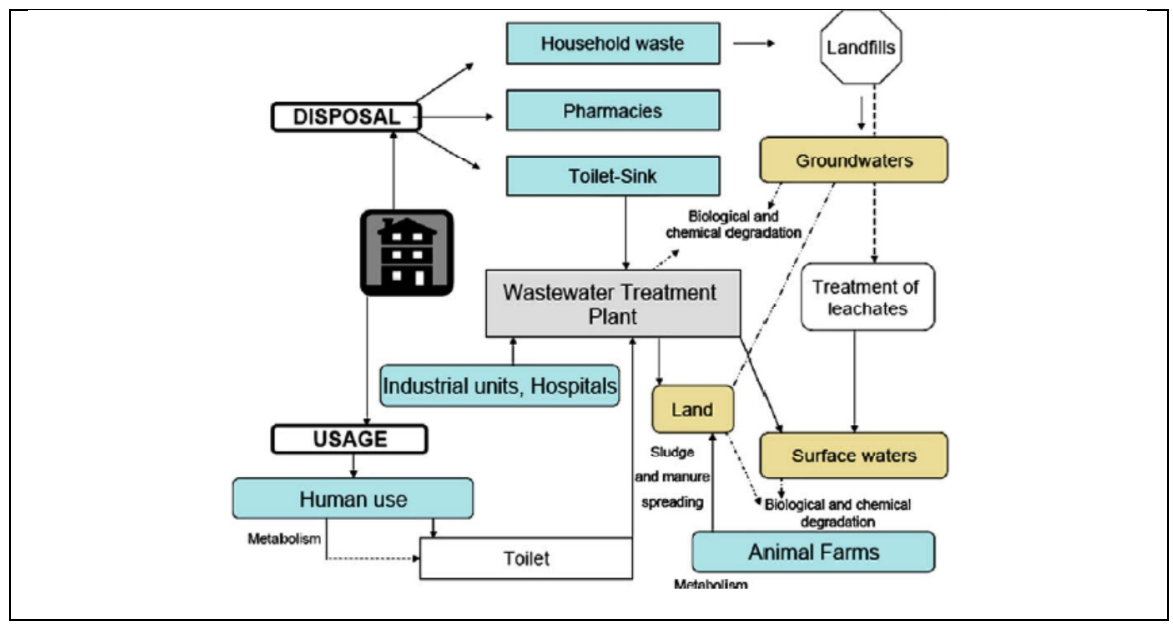

Figure 1. Sources of emerging pollutants in water (Nikolaou et al., 2007)

Scientific research on emerging pollutants has been expanding in global scale, aiming to increase the knowledge on the sources, occurrence, fate and toxicity of these compounds as well as of their transformation products. In parallel, great efforts are being devoted to the analytical part, in order to develop and validate appropriate and sensitive analytical methods (Fatta-Kassinos et al., 2007; Kostopoulou and Nikolaou, 2008).

Pharmaceuticals and related compounds are a large category of emerging pollutants that has become a subject of scientific attention in particular for environmental samples quite recently. Research on these compounds has revealed their increasing occurrence in environmental samples as well as their adverse effects on organisms. They are used worldwide in large amounts, comparable to the amounts of pesticides, and in some countries some of them are even sold without the requirement of a prescription. They enter the water cycle via the pathways described in Figure 1, including their disposal in landfills or in wastewater (Nikolaou et al., 2007).

Meanwhile there is lack of knowledge for long-term effects of the exposure to low concentrations of such compounds and especially their mixtures. The determination of the toxic effects of pharmaceuticals, transformation products and mixtures in the environment is a subject requiring urgent attention, and simultaneously a great challenge for scientists, taking also into account that they are present in trace concentrations (Kostopoulou and Nikolaou, 2008).

There are still many gaps in the fields of analytical method development and optimization, ecotoxicological data and risk assessment, data on occurrence and fate of pharmaceutical compounds in the environment and in biota. Research has shown that these compounds are not effectively removed during conventional wastewater treatment, therefore they are released into the surcace waters, as mixtures of parent compounds, their metabolites and transformation by-products. 
Some pharmaceuticals can persist in the environment and, either via the food chain or via drinking water, can make their way back to humans, while the properties and fate of metabolites and transformation products are still largely unknown (Fatta et al., 2007).

Recent research has shown that some of these compounds are associated with adverse developmental effects in aquatic organisms at environmentally relevant concentrations (Khetan and Collins, 2007). The effects of human exposure to low-dose mixtures of pharmaceuticals, as well as those of the exposure to low-dose pharmaceuticals mixed with other low-dose synthetic pollutants have not yet been determined. Concern is raised about practices such as wastewater reuse for irrigation, discharge into the sea and other aquatic environments, groundwater replenishment, etc. Khetan and Collins (2007) and Fatta-Kassinos et al. (2010) emphasize that such practices can raise concerns about the potential effects on non-target organisms, including plants, animals, and humans.

In order to find the answers to the concerns described above, researchers are working on the development and optimization of analytical methods, and their application for the determination of pharmaceuticals in water and wastewater. During the last years, a large number of related papers has been published, increasing the knowledge of the levels and fate of individual compounds in the environment (Jux et al., 2002; Wiegel et al., 2004; Benz et al., 2005; Thaker, 2005; Moldovan, 2006). However, research also has shown the existence and formation of metabolites and transformation products of pharmaceuticals and related compounds in water and wastewater (Calza et al., 2004a;b; Munoz and von Sonntag, 2000; Snyder et al., 2006; Vogna et al., 2002; 2004; Andreozzi et al., 2003). Further improvements of the instrumentation and analytical techniques are being applied, aiming to shed more light to their identificarion, determination of their formation mechanisms and fate in the environment, as well as to their levels and related potential adverse effects.

The aim of this paper is to discuss the recent research on pharmaceuticals in environmental waters, focusing on the analytical characterization of these compounds and their oxidation/degradation products, new findings, procedures, analytical problems and challenges.

\section{ANALYSIS OF PHARMACEUTICALS AND TRANSFORMATION PRODUCTS IN WATER SAMPLES}

\section{Analytical methods}

Different analytical methods have been developed and applied, for the analysis of different groups of pharmaceuticals, according to the properties of the compounds. In order to save analysis time and effort, "multi-residue" methods have also been applied for the simultaneous analysis of a large number of pharmaceuticals belonging to different categories (Gros et al., 2006; Botitsi et al. 2007). Multi-residue methods provide the advantage of obtaining faster and easier results for the levels of different compounds in water samples. However the challenge for such methods is that they include a compromise for the simultaneous analysis of compounds with different physico-chemical properties, in regard to the experimental conditions of the analytical method, in order to accurately determine all analytes in a single run.

\section{Sample Preparation}

The sample preparation for the analysis of pharmaceuticals includes the extraction of all target analytes from the sample, with solid phase extraction (SPE) with the appropriate material according to the analytes (Gros et al., 2006b; Petrovic et al., 2006). A combination of two SPE materials can also be performed, either in series or classifying the analytes into two or more groups, according to their physico-chemical properties. Cartridges commonly used are Oasis HLB or C18. The Oasis HLB show better performance at neutral sample $\mathrm{pH}$, while when using $\mathrm{C} 18$, sample $\mathrm{pH}$ needs to be adjusted depending on the acidic, neutral or basic nature of the analytes. Other cartridges used are Lichrolut ENV+, Oasis MCX and StrataX (Kostopoulou and Nikolaou, 2008).

After extraction, elution of the analytes from the cartdrige is performed with pure organic solvents, mostly methanol or acetonitrile. Analyte losses can occur in some cases, for example in the case of antibiotics, in particular tetracycline, sulphonamides and polypeptide antibiotics, Na2EDTA is added as chelating agent before extraction, to avoid formation of complexes of the antibiotics with metal 
ions. Particular attention is required also for the container material, with PTFE being preferrable than glass, because the compounds tend to bind to the glass, resulting in significant losses (Petrovic et al., 2006; Diaz-Cruz and Barcelo, 2006).

Alternatively to SPE, Molecularly Imprinted Polymers (MIPs) or immunosorbents can be used for the extraction. These extraction methods have high selectivity, therefore they have found wide application for compounds such as clenbuterol, aniline $\beta$-agonists, tetracycline and sulphonamide antibiotics, $\beta$-agonists and $\beta$-antagonists from biological samples, while some applications have been reported also in environmental samples (Bravo et al., 2007; O'Connor and Aga, 2007).

After extraction, a purification step is usualy included in the analytical methods, in order to minimise the matrix effects, especially in complex environmental samples. For the purification (cleanup) of the extract, the extracts are usually diluted with an appropriate volume of MilliQ water, until the organic solvent content is below $10 \%$ and SPE is applied, using mostly the same cartridges and conditions as the analysis of pharmaceuticals in water samples (Jacobsen et al., 2004).

\section{Analytical determination}

For the analytical determination of pharmaceuticals and related compounds, LC-MS/MS has become the preferable analysis method, due to its versatility, specificity and selectivity, gradually replacing GC-MS and LC-MS. However GC-MS can still be successfully applied in some cases, especially for non-polar and volatile pharmaceutical compounds. The disadvantage of GC-MS application is that it requires a time-consuming derivatization step, during which there are risks of analyte losses (Kolpin et al., 2002; Weigel et al., 2004).

Among LCMS/MS techniques, triple quadrupole (QqQ) and ion trap (IT) instruments are in common use, and they permit the detection of pharmaceuticals at the $\mathrm{ng} \mathrm{L}^{-1}$ range. More recent approaches in LC-MS/MS are linear ion traps (LITs), new generation triple quadrupoles, and hybrid instruments, such as quadrupole-time of flight (QqTOF) and quadrupole-linear ion trap (QqLIT) (Perez and Barcelo, 2007). QqTOF instruments have been used for the elucidation of structures proposed for transformation products (Stolker et al., 2004; Eichhorn et al., 2005; Gomez et al., 2007) (Table 1). The application of QqLIT methods includes the determination of diclofenac, carbamazepine and iodinated X-ray contrast media (Seitz et al., 2006) as well as $\beta$-blockers in wastewater (Nikolai et al., 2006).

Another technique used is reversed-phase LC, with C18 columns. lonpair reversed-phase LC with a Phenyl-Hexyl column has also been used (Quintana and Reemtsma, 2004). The mobile phases mostly used are acetonitrile, methanol, or mixtures. The sensitivity of the method can be improved with use of mobile phase modifiers, buffers and acids, usually ammonium acetate, tri-n-butylamine (TrBA), formic acid and acetic acid (Gros et al., 2006b).

\section{Examples of pharmaceuticals and related compounds detected in aqueous samples}

\section{Pharmaceuticals}

The occurrence of pharmaceuticals in environmental waters has been confirmed by a large number of studies worldwide. Their concentrations usually range at the $\mathrm{ng} \mathrm{L}^{-1}-\mathrm{Mg} \mathrm{L}^{-1}$ range in surface waters. Table 1 presents an indicative list of the range of concentratons of pharmaceuticals detected in river waters in different countries.

\section{Transformation products of pharmaceuticals}

Pharmaceuticals in the water cycle, can undergo biotic or abiotic degradation/elimination processes Biotic degradation has been observed for acetaminophen. Lin et al. (2010), however for most of the drugs is considered to be less important than abiotic degradation processes (e.g. hydrolysis, photolysis, redox reactions, etc). Especially important processes are those of direct photolysis and indirect photodegradation, including reaction with photo-excited dissolved organic matter (DOM), and transient reactive species, for example singlet oxygen (1O2), the hydroxyl radical (HO•), peroxy radicals $(\cdot \mathrm{OOR})$, and solvated electrons (eaq-), generated by irradiation of various aquatic components (DOM, NO3-, $\mathrm{Fe} 3+$ ). The molecular structure of pharmaceuticals that enhances their photodegradation, contains aromatic rings, heteroatoms, and other functional groups that either directly absorb solar radiation or react with the above-mentioned photogenerated transient species 
in natural waters. During most of these degradation procedures, transformation products of the parent compounds can be formed (Konstantinou et al., 2009).

The improvement of available analytical instrumentation and the optimization of sample preparation and analysis procedures have dramatically increased the sensitivity of the analysis and in parallel have provided the ability to identify and quantify new compounds, beloging to the categories of metabolites and transformation products of the parent compounds, that are detected in surface waters and wastewater with increasing frequency. Recently, there have been several studies on the metabolites and oxidation products of pharmaceuticals (Perez and Barcelo, 2007, Gomez et al., 2007). Such studies are important because they provide information on the fate of pharmaceuticals, and identify the mechanisms through which the transformation products are formed. In parallel, further research is needed on the possible effects of the transformation products on the environment and human health.

Table 1. Levels of pharmaceuticals detected in river waters

\begin{tabular}{|c|c|c|c|}
\hline Pharmaceuticals & Sampling site & Levels & Reference \\
\hline Diclofenac & Germany, 27 rivers & $15 \mu \mathrm{g} \mathrm{L}^{-1}$ & Jux et al., 2002 \\
\hline $\begin{array}{l}\text { Diclofenac, ibuprofen, carbamazepine, } \\
\text { antibiotics, lipid regulators }\end{array}$ & $\begin{array}{l}\text { Germany, Elbe } \\
\text { river }\end{array}$ & $20-140 \mathrm{ng} \mathrm{L}^{-1}$ & Wiegel et al., 2004 \\
\hline $\begin{array}{l}\text { lbuprofen, ketoprofen, naproxen, } \\
\text { diclofenac, atenolol, metoprolol, } \\
\text { propranolol, trimetoprim, } \\
\text { sulfametoxazole, carbamazepine, } \\
\text { gemfibrozil }\end{array}$ & Sweden, Hoje river & $0.12-2.2 \mu \mathrm{g} \mathrm{L}^{-1}$ & Benz et al., 2005 \\
\hline Carbamazepine & USA, 44 rivers & $60 \mathrm{ng} \mathrm{L}^{-1}$ & Thaker, 2005 \\
\hline $\begin{array}{l}\text { Acetylaminophenazone, } \\
\text { pentaoxifilline, ibuprofen, } \\
\text { formylaminophenazone, p- } \\
\text { chlorophenyl sulfone, N,N-bis(3,3- } \\
\text { dimethyl-2-oxetanyl)-3,3-dimethyl-2- } \\
\text { oxetanamine, triclosan, } \\
\text { carbamazepine, codeine, diazepam, } \\
\text { cyclophosphamide }\end{array}$ & $\begin{array}{l}\text { Romania, Somes } \\
\text { river }\end{array}$ & $300-10000 \mathrm{ng} \mathrm{L}^{-1}$ & Moldovan, 2006 \\
\hline $\begin{array}{l}\text { Clofibric acid, ibuprofen, gemfibrozil, } \\
\text { naproxen, mefenamic acid, diclofenac }\end{array}$ & $\begin{array}{l}\text { South China, Pearl } \\
\text { rivers }\end{array}$ & $17-685 \mathrm{ng} \mathrm{L}^{-1}$ & Zhao et al., 2009 \\
\hline $\begin{array}{l}\text { Carbamazepine, diazepam, fenofibric } \\
\text { acid, propranolol, trimethoprim } \\
\text { sulfamethoxazole }\end{array}$ & $\begin{array}{l}\text { Portugal, Douro } \\
\text { River }\end{array}$ & $3-178 \mathrm{ng} \mathrm{L}^{-1}$ & $\begin{array}{l}\text { Madureira et al., } \\
2010\end{array}$ \\
\hline $\begin{array}{l}\text { ibuprofen, diclofenac, naproxen, } \\
\text { atenolol, frusemide (furosemide), } \\
\text { gemfibrozil hydrochlorthiazide }\end{array}$ & $\begin{array}{l}\text { Spain (Madrid), } \\
\text { rivers Jarama, } \\
\text { Manzanares, } \\
\text { Guadarrama, } \\
\text { Henares, Tagus }\end{array}$ & $2 \mathrm{ng} \mathrm{L}^{-1}-18 \mu \mathrm{g} \mathrm{L}^{-1}$ & $\begin{array}{l}\text { Valcarcel et al., } \\
\qquad 2011\end{array}$ \\
\hline $\begin{array}{l}\text { Ibuprofen, paracetamol, } \\
\text { sulfamethoxazole, zidovudine }\end{array}$ & $\begin{array}{l}\text { Kenya, Nairobi } \\
\text { river }\end{array}$ & $10-30 \mu \mathrm{g} \mathrm{L}^{-1}$ & Koreje et al., 2012 \\
\hline
\end{tabular}

A transformation product of carbamazepine, carbamazepine 10,11-epoxide, has been detected in wastewater samples at levels far lower than the parent compound. Salicylic acid, the main metabolite of acetylsalicylic acid (ASA) has been detected in treated wastewater. ASA is easily degraded by deacetylation into salicylic acid and two other metabolites, ortho-hydroxyhippuric acid and the hydroxylated metabolite gentisic acid, which are also likely to be detected in aqueous samples. 1,7-dimethylaxanthine, a metabolite of caffeine has also been detected in treated wastewater. Clofibric acid, the major metabolite of lipid regulators (e.g., clofibrate, etofibrate, 
etofyllinclofibrate), and fenofibric acid, the major metabolite of fenofibrate, have also been detected (Stumpf et al., 1999; Gomez et al., 2007).

Transformation products of pharmaceuticals formed during different oxidation processes applied for wastewater treatment have been identified as presented in Table 2.

Table 2. Oxidation products of pharmaceuticals

\begin{tabular}{|c|c|c|c|}
\hline Pharmaceutical & $\begin{array}{l}\text { Oxidation } \\
\text { process }\end{array}$ & Oxidation product & Reference \\
\hline Sulfadiazine & $\mathrm{TiO}_{2} / \mathrm{hv}$ & 4-methyl-2-amino-pyrimidine & Calza et al., 2004 \\
\hline Sulfamethoxazole & Ozonation & Hydroxylamine & $\begin{array}{l}\text { Munoz and von } \\
\text { Sonntag, } 2000\end{array}$ \\
\hline Sulfamethoxine & $\mathrm{TiO}_{2} / \mathrm{hv}$ & $\begin{array}{l}\text { 2,6-dimethoxy-4- } \\
\text { aminopyrimidine } \\
\text { 2-aminothiazole }\end{array}$ & Calza et al., 2004 \\
\hline Sulfathiazole & $\mathrm{TiO}_{2} / \mathrm{hv}$ & $\begin{array}{l}\text { 2,6-dimethoxy-4- } \\
\text { aminopyrimidine } \\
\text { 2-aminothiazole }\end{array}$ & Calza et al., 2004 \\
\hline Sulfamerazine & $\mathrm{TiO}_{2} / \mathrm{hv}$ & 4-methyl-2-aminopyrimidine & Calza et al., 2004 \\
\hline Busperidone & $\mathrm{TiO}_{2} / \mathrm{hv}$ & $\begin{array}{l}\text { Hydroxybusperidone } \\
\text { Dihydroxybusperidone } \\
\text { Dipyrimidinylbusperidone } \\
\text { 1-pyrimidinyl piperazine } \\
\end{array}$ & Calza et al., 2004b \\
\hline Carbamazepine & Ozonation & $\begin{array}{l}\text { 1-(2-benzaldehyde)-4- } \\
\text { hydro(1H,3H)quinazoline-2- } \\
\text { one } \\
\text { 1-(2-benzaldehyde)- } \\
\text { (1H,3H)quinazoline-2,4-dione } \\
\text { 1-(2-benzoic acid)- } \\
\text { (1H,3H)quinazoline-2,4-dione } \\
\text { Acridine, salicylic acid, } \\
\text { catechol, anthranilic acid }\end{array}$ & Snyder et al., 2006 \\
\hline Paracetamol & Ozonation & $\begin{array}{l}\mathrm{N}-4 \text {-hydroxyphenyl-acetamide } \\
2-[(2,6-\text { dichlorophenyl)- } \\
\text { amino]-5-hydroxyphenylacetic } \\
\text { acid } \\
\text { 2,5-dihydroxyphenylacetic } \\
\text { acid }\end{array}$ & $\begin{array}{c}\text { Andreozzi et al., } 2003 \\
\text { Vogna et al., } 2002\end{array}$ \\
\hline Phenazone & Chlorination & $\begin{array}{l}\text { Chloro-hydroxy-phenazone } \\
\text { N-demethyl-chloro-hydroxy- } \\
\text { phenazone }\end{array}$ & Rodil et al., 2012 \\
\hline Propyphenazone & Chlorination & $\begin{array}{l}\text { N-demethyl-hydroxy- } \\
\text { propyphenazone } \\
\text { N-demethyl-chloro-hydroxy- } \\
\text { propyphenazone }\end{array}$ & Rodil et al., 2012 \\
\hline Dichlofenac & Denitrification & Nitro-Diclofenac & Barbieri et al., 2012 \\
\hline Sulfamethoxazole & Denitrification & 4-Nitro-Sulfamethoxazole & Barbieri et al., 2012 \\
\hline
\end{tabular}

Recent research on the toxicity of transformation products, performed by bioassays on bacteria, algae, rotifers, and microcrustaceans, as well as by the SOS chrom-test and the Ames fluctuation test, suggest that acute and chronic toxicity of the photoproducts of diclofenac, naproxen, and the fibrates, can be greater than the parent compounds, while genotoxic and mutagenic effects cannot be excluded as well (Konstantinou et al., 2009). 


\section{Illicit drugs and their metabolites}

Among the applications of LC-MS/MS methods is the determination of the occurrence of illicit drugs and metabolites in water and wastewater. Cocainics, amphetamine-like compounds, opiates, cannabinoids, and lysergics have been determined. Cocaine and its main metabolite benzoylecgonine (BE), has been detected at levels up to $\mu \mathrm{g} \mathrm{L}^{-1}$. while cocaethylene (CE), product of cocaine, was also detected. CE is a transesterification product formed when cocaine is consumed together with ethanol, and transforms rapidly into metabolites such as norcocaethylene and ecgonine ethyl ester. The cocaine metabolites norcocaine and norbenzoylecgonine, have also been determined in wastewater in Italy with maximum concentration $40 \mathrm{ng} \mathrm{L}^{-1}$ (Hada et al., 2000; Santos and Galceran, 2002; Petrovic et al., 2006).

Morphine has also been detected in wastewater at high $\mathrm{ng} \mathrm{L}^{-1}$ levels. Heroine was detected at very low concentrations due to its low consumption and rapid hydrolysis to morphine and 6acetylmorphine. Research in Italy and in Switzerland showed that methadone was present at lower ng $L^{-1}$ levels than its pharmacologic inactive metabolite 2-ethylidine-1,5-dimethyl-3,3diphenylpyrrolidine perchlorate (EDDP). Lysergic acid diethylamide (LSD) and its metabolites norLSD and nor-iso LSD (nor-LSD) and 2-oxo-3-hydroxy-LSD (O-H-LSD), have also been detected at very low concentrations (Petrovic et al., 2006).

The drugs phenylethylamine ephedrine, 3,4 -methylenedioxymetamphetamine hydrochloride (MDMA or "ecstasy"), methylenedioxyethylamphetamine (MDE, MDEA or "Eve") and 3,4methylenedioxyamphetamine (MDA or "Love pills", and metabolite of both MDE and MDMA), have been detected frequently at the $\mathrm{ng} \mathrm{L}^{-1}$ level. The metabolites of the active constituent of Cannabis $\triangle 9$-tetrahydrocannabinol (THC), 11-nor-9 carboxy THC (nor-THC) and 11-hydroxy-THC (OH-THC), have also been detected (Stuber and Reemtsma, 2004; Santos and Galceran, 2002).

\section{Analytical aspects and future challenges}

Pharmaceuticals and related compounds are one of the most important new categories of emerging pollutants. Their occurrence has been reported in a variety of environmental samples, in surface waters and wastewater, by a large number of studies (Kolpin et al., 2002; Jacobsen et al., 2004; Gros et al., 2006; Botitsi et al., 2007; O'Connor et al., 2007; Zhao et al., 2009; Valcarcel et al., 2011; Koreje et al., 2012). However their accurate quantification, especially in the trace levels they occurr in the aquatic environment can be an analytical challenge, taking into account the matrix effects too. The rapid development of detection techniques such as gas and liquid chromatography (GC and LC) in combination with modern extraction, derivatization, and clean-up methods provide the opportunity to quantify many pharmaceutical compounds and metabolites down to ng L-1 levels, and thus are very important towards the effort to determine the actual risks involved with the presence of these pollutants in the environment.

Relevant research during the last years has focused on the optimization of analytical techniques, regarding the equipment used, as well as the sample preparation, extraction, derivatization and clean-up procedures (Stolker et al., 2004; Perex and Barcelo, 2007; Kostopoulou and Nikolaou, 2008).

Regarding the instrumentation, the developed methodologies utilized both GC and LC instruments for the analysis of pharmaceuticals in environmental samples. GC is preferable for the analysis of non-polar and volatile compounds, but it can be applied for the analysis of low concentrations of polar pharmaceuticals by addition of a derivatization step (Figure 2). The advantages of GC include very high selectivity and resolution, good accuracy and precision, wide dynamic range, and high sensitivity (Hada et al., 2000; Cochran, 2002). The GC×GC instrumentation, that has more recently found application, provides even better separation and identification of the analytes in complex environmental samples (Hyotylainen et al., 2002). On the other hand, LC is the preferred technique for separation of polar pharmaceuticals, and has the advantage of shorter analysis time, without the need for derivatization. For the detection of pharmaceuticals, tandem MS-MS is increasingly being used, replacing other detectors, in combination with LC (fluorescence, UV, PAD) and GC (FID, ECD) (Fatta et al., 2007). 


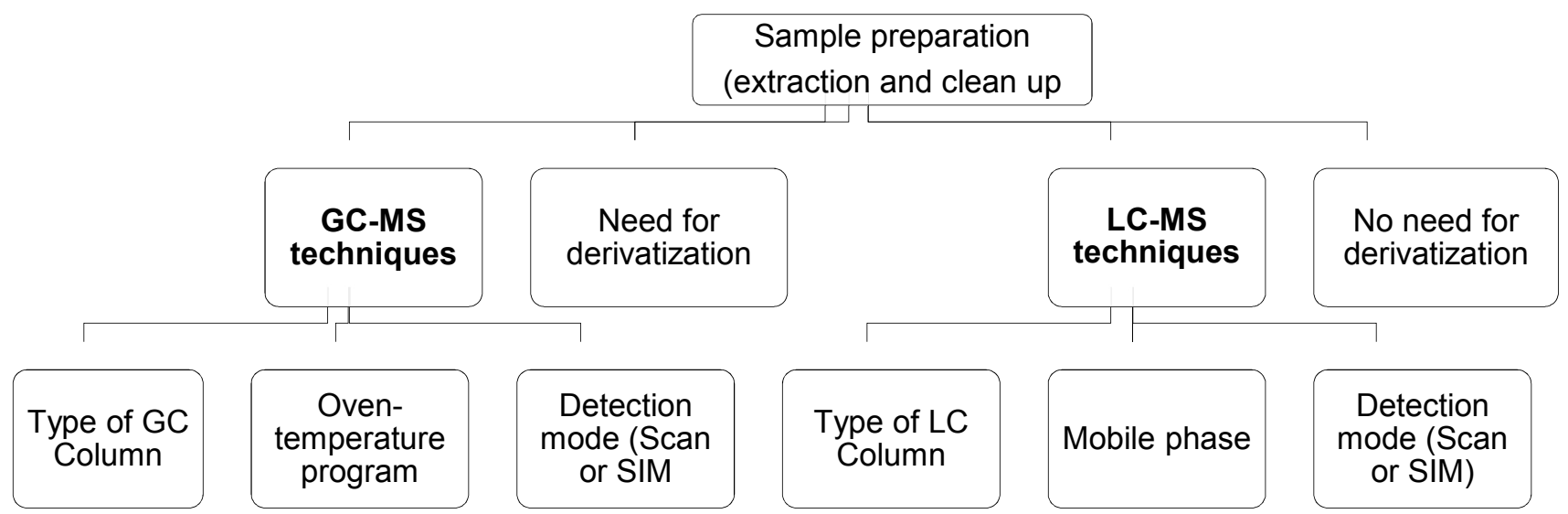

Figure 2. Analysis options for pharmaceuticals and instrumental parameters

The part of sample-preparation is critical in order to achieve high method sensitivity. A significant part of analytical research has been devoted to the various alternatives and optimizations of this part, starting from the extraction of pharmaceuticals from the sample into a small volume of solvent with either SPE or SPME, liquid-phase microextraction (LPME) or lyophilization, and combination of different SPE materials in series (Gros et al., 2006; Kostopoulou and Nikolaou, 2008). There has been much research to identify the optimum SPE stationary phases. The most commoly used materials are hydrophilic-lipophilic balanced polymers and silica-based bonded phase with strong hydrophobicity. Other stationary phases used for pre-concentration and clean up of pharmaceuticals in aqueous samples are strong cationexchange mixed-mode polymeric sorbent, or polystyrenedivinylbenzene resin modified with carboxyl groups (Kostopoulou and Nikolaou, 2008).

The next investigated step is elution of the analytes. The most commonly used elution solvents are methanol, acetone, and ethyl acetate. Automation can also improve both extraction and elution steps, as automated SPE can enable direct injection of untreated samples, automatically conducting conditioning, washing, and elution steps, requiring less time and lower amounts of solvent, while simultaneously improving reproducibility and reducing health risks during analysis (Fatta et al., 2007).

An alternative extraction technique that gained attention during the recent years for the analysis of pharmaceuticals is SPME. During SPME, the analytes are extracted directly from a sample on to an absorptive layer of sorbent coated on a fiber. The quantity of the compound extracted by the fiber is proportional to its concentration in the sample, as long as equilibrium is reached or, for shortterm pre-equilibrium, with the help of convection or agitation. After extraction, the SPME fiber is transferred to the injection port of the GC or LC for analysis. In this way, SPME eliminates the need for solvents as well as the assosiated environmental and health risks, and combines sampling, isolation and enrichment in one step (Ouyang and Pawliszyn, 2006).

Derivatization, an analysis step used before GC analysis and after extraction, is another factor that scientists are trying to optimize, by use of different amounts and reaction times and conditions, for different derivatization agents. In the case of SPE, derivatization is performed after elution, while in the case of SPME there are the options of direct, or on-fiber derivatization. In direct derivatization the derivatizing agent is first added to the sample vial and the derivatives are then extracted by the SPME fiber coating. In on-fiber derivatization, the derivatizing agent is loaded on the fiber, which is subsequently exposed to the sample and extracted (Ouyang and Pawliszyn, 2006).

In any case, the effectiveness of derivatization depends on the types of pharmaceuticals studied and on the type of derivatizing agent. The most common derivatizing agents used are acid anhydrides, benzyl halides, alkylchloroformates, and diazomethane, although use of diazomethane has been limited in recently developed methods because of its toxic and carcinogenic properties. N-Methyl-N(trimethylsilyl)-trifluoroacetamide) (MSTFA) has been reported to perform well as a derivatizing agent for the determination of metoprolol, nadolol, and propranolol (recoveries 85-94\%) (Huggett et al., 2003). Butyldimethylsilylation was reported to perform better than trimethylsilylation, as it forms more stable derivatives after SPE (Rodriguez et al., 2003). During derivatization with TMAH (tetramethylammonium hydroxide), aniline can be formed as a by-product, which can interfere with compounds with similar retention times. An injection-port derivatization technique has also been 
reported, having the advantage of avoiding the handling of hazardous derivatizing agents (Lin et al., 2005).

There has been much research on derivatization and it is still a challenge to identify the best combinations, especially for the newly identified trasformation products of pharmaceuticals. In some cases, derivatization can be incomplete, causing problems in the analytical method, for example for $\beta$-blockers atenolol and sotalol. Moreover, some compounds are thermolabile and decompose during GC analysis (e.g., carbamazepine forms iminostilben as a degradation product) (Petrovic et al., 2003).

Another analytical problem that researchers have to deal with, during the optimization of pharmaceutical analysis methods, is the occurrence of matrix effects. Matrix effects should be eliminated, if possible, or at least minimized, because they negatively affect the sensitivity, linearity, accuracy, and precision of the analytical methods. Techniques applied for the reduction of matrix effects are selective extraction and sample clean-up after extraction. However, during application of all these techniques, analyte losses can occur, as additional steps are being added to the sample preparation, while, in parallel, the time and effort required is increased (Fatta et al., 2007). To avoid such complications, other methods to reduce matrix effects have been applied, related mostly to the calibration of the instruments: external calibration with matrix-matched samples, standard addition or internal standard calibration using structurally similar unlabeled pharmaceuticals or isotopically labeled standards, dilution of sample extracts, and isotope dilution (use of an isotopically labeled standard for each target compound) (Alder et al., 2004, Van de Steene et al., 2006). Relevant research is continuing, in order to identify the optimum combination of techniques, depending on the compounds studied, the analytical methodology applied, and the sample matrix.

\section{CONCLUSIONS}

Pharmaceuticals and related compounds, as well as their metabolites and transformation products, increasingly occur as emerging pollutants in the water cycle, due to human activities, and physicochemical or biological processes. A significant number of new compounds/transformation products have been identified during the recent years. Their presence, concentration levels, mechanisms of formation/transformation, fate and possible toxic effects are subject of current research worldwide. In order to fill the gaps of information on all these issues, accurate analytical methods for the determination of these diverse groups of pollutants are required. However, their determination in trace levels, especially in complex environmental samples containing a variety of organic compounds, is a challenging task. New analytical methods and procedures, including sample preparation and analysis instrumentation, are being developed, evaluated and optimized for this purpose, aiming to reveal the answers for many questions about the parent compounds and especially the transformation products, and eventually the risks they pose for the aquatic environment and human.

\section{REFERENCES}

Alder L., Luderitz S., Lindtner K., Stan H.J. (2004) The ECHO technique--the more effective way of data evaluation in liquid chromatography-tandem mass spectrometry analysis, $J$ Chromatogr $A, 1058,67-$ 79.

Andreozzi R., Caprio V., Marotta R., Vogna D. (2003) Paracetamol oxidation from aqueous solutions by means of ozonation and $\mathrm{H}_{2} \mathrm{O}_{2} / \mathrm{UV}$ system, Water Res., 37, 993-999.

Babi K.G., Koumenidis K.M., Makri C.A., Nikolaou A.D., Lekkas T.D. (2011) Adsorption capacity of GAC pilot filter-adsorber and postfilter- adsorber for individual THMs from drinking water, Athens, Global NEST Journal, 13(1), 50-58.

Barbieri M., Carrera J., Ayora C., Sanchez-Vila X., Licha T., Nödler K., Osorio V., Pérez S, KöckSchulmeyer M., de Alda M.L., Barceló D. (2012) Formation of diclofenac and sulfamethoxazole reversible transformation products in aquifer material under denitrifying conditions: Batch experiments, Sci. Tot. Environment, 426, 256-263.

Benz D., Paxéus N.A., Ginn T.R., Loge F.J. (2005) Occurrence and fate of pharmaceutically active compounds in the environment, a case study: Hoje River in Sweden, J Hazard Mater., 122,195-204.

Bloutsos A.A., Giannopoulos P.C. (2011) Concentrations of selected toxic elements in airborne particulates of Patras, Greece, Global NEST Journal, 13(2), 109-118. 
Botitsi, E., Frosyni, C., Tsipi, D. (2007) Determination of pharmaceuticals from different therapeutic classes in wastewaters by liquid chromatography-electrospray ionization-tandem mass spectrometry, Anal Bioanal Chem, 387, 1317-1327.

Bravo, J.C., Garcinuno, R.M., Fernandez, P., Durand, J.S. (2007) A new molecularly imprinted polymer for the on-column solid-phase extraction of diethylstilbestrol from aqueous samples, Anal Bioanal Chem, 388, 1039-1045.

Calza, P., Medana, C., Pazzi, M., Baiocchi, C., Pelizzetti, E. (2004) Photocatalytic transformations of aminopyrimidines on TiO2 in aqueous solution, Appl Catal B Environ, 52, 267-274.

Calza, P., Pazzi, M., Medana, C., Baiocchi, C., Pelizzetti, E. (2004) The photocatalytic process as a tool to identify metabolitic products formed from dopant substances: the case of buspirone, $J$ Pharm Biomed Anal, 35, 9-19.

Cochran JW (2002) Fast Gas Chromatography-Time-of-Flight Mass Spectrometry of Polychlorinated Biphenyls and Other Environmental Contaminants, J Chromatogr Sci, 40(5):254-268.

Diaz-Cruz, M.S., Barcelo, D. (2006) Determination of antimicrobial residues and metabolites in the aquatic environment by liquid chromatography tandem mass spectrometry, Anal Bioanal Chem, 386, 973-985.

Eichhorn, P., Ferguson, P.L., Perez, S., Aga, D.S. (2005) Application of ion trap-MS with H/D exchange and QqTOF-MS in the identification of microbial degradates of trimethoprim in nitrifying activated sludge, Anal Chem, 77, 4176-4184.

Ekmekyapar F., Sabudak T., Seren G. (2012) Assessment of heavy metal contamination in soil and wheat (Triticum Aestivum L.) plant around the Corlu-Cerkezkoy highway in Thrace region, Global NEST Journal, 14(4), 496-504.

Fatta-Kassinos D, Kalavrouziotis IK, Koukoulakis PH, Vasquez MI (2011) The risks associated with the wastewater reuse and xenobiotics in the agroecological environment, Sci Total Environ, 409, 35553563.

Fatta, D., Achilleos, A., Nikolaou A., and Meric S. (2007) Analytical methods for tracing pharmaceutical residues in water and wastewater, Trends in Analytical Chemistry, 26(6), 515-533.

Gomez M.J., Martinez Bueno M.J., Lacorte S., Fernandez-Alba A.R., Aguera A. (2007) Pilot survey monitoring pharmaceuticals and related compounds in a sewage treatment plant located on the Mediterranean coast, Chemosphere, 66, 993-1002

Gomez, M.J., Malato, O., Ferrer, I., Aguera, A., Fernandez-Alba, A.R. (2007) Solid-phase extraction followed by liquid chromatography-time-of-flight-mass spectrometry to evaluate pharmaceuticals in effluents. A pilot monitoring study, J Environ Monit, 9, 718-729.

Gros, M., Petrovic, M., and Barcelo, D. (2006a) Development of a multi-residue analytical methodology based on liquid chromatography-tandem mass spectrometry (LC-MS/MS) for screening and trace level determination of pharmaceuticals in surface and wastewaters, Talanta, 70, 678-690.

Gros, M., Petrovic, M., Barcelo, D. (2006b) Multi-residue analytical methods using LC-tandem MS for the determination of pharmaceuticals in environmental and wastewater samples: A review, Anal Bioanal Chem, 386, 941-952.

Hada, M., Takino, M., Yamagami, T., Daishima, S., Yamaguchi, K. (2000) Trace analysis of pesticide residues in water by high-speed narrow-bore capillary gas chromatography-mass spectrometry with programmable temperature, J Chromatogr A, 874, 81-90.

Hadjibiros K., Dermatas D., Laspidou C.S. (2011) Dehalogenation of polychlorinated biphenyls (PCB) by nucleofile reactants at the presence of ionic liquids and under application of microwaves, Global NEST Journal, 13(2), 150-161.

Hale S.E., Kwon S., Ghosh U., Wernet D. (2010) Polychlorinated biphenyl sorption to activated carbon and the attenuation caused by sediment, Global NEST Journal, 12(3) 318-326.

Himmelsbach M, Buchberger W, Klampfl CV (2006) Determination of antidepressants in surface and waste water samples by capillary electrophoresis with electrospray ionization mass spectrometric detection after preconcentration using off-line solid-phase extraction, Electrophoresis, 27, 12201226.

Huggett DB, Khan IA, Foran CM, Schlenk D (2003) Determination of Beta-Adrenergic Receptor Blocking Pharmaceuticals in United States Wastewater Effluent, Environ Pollut, 121,199-205.

Hyotylainen T, Kallio M, Hartonen K, Jussila M, Palonen S, Riekkola ML (2002) Modulator design twodimensional for comprehensive gas chromatography: Quantitative analysis of polyaromatic hydrocarbons and polychlorinated biphenyls, Anal Chem, 74, 4441-4446

Jacobsen, A.M, Halling-Sorensen, B., Ingerslev, F., Hansen, S.H. (2004) Simultaneous extraction of tetracycline, macrolide and sulfonamide antibiotics from agricultural soils using presurrised liqiod 
extraction followed by soild-phase extraction and liqiod chromatography-tandem mass spectrometry, J Chromatogr A, 1038, 157-170.

Jux U., Baginski R.M., Arnold H.G., Krönke M., Peter N. (2002) Detection of pharmaceutical contaminations of river, pond, and tap water from Cologne (Germany) and surroundings, Int $J$ Hygiene Environ Health, 205(5), 393-398.

Kalantzi O.I., Alcock R.A (2012) Short-chain chlorinated paraffins in biota - levels and effects, Global NEST Journal, 14(1) 66-71.

Kalantzi O.I., Siskos P.A. (2011) Sources and human exposure to polybrominated diphenyl ethers, Global NEST Journal, 13(2), 99-108.

Karapanagioti H.K., Ogata Y., Takada H. (2010) Eroded plastic pellets as monitoring tools for polycyclic aromatic hydrocarbons (PAH): laboratory and field studies, Global Nest Journal, 12(3), 327-334.

Khetan SK, Collins TJ (2007) Human pharmaceuticals in the aquatic environment: a challenge to green chemistry, Chem Rev, 107, 2319-2364.

Kolpin, D.W., Furlong, E.T., Meyer, M.T., Thurman, E.M., Zaugg, S.D., Barber, L.B., Buxton, H.T. (2002) Pharmaceuticals, hormones, and other organic wastewater contaminants in U.S. streams, 19992000--A national reconnaissance, Environ Sci Technol, 36, 1202-1211.

Konstantinou IK, Lambropoulou DA, Albanis TA (2009) In: Fatta-Kassinos D, Bester K, Kümmerer K (eds), Xenobiotics in the urban water cycle, Environ. Pollut., 16, 179-194.

Koreje K., Demeestere K., De Wispelaere P., Vergeynst L., Dewulf J., Van Langenhove H. (2012) From multi-residue screening to target analysis of pharmaceuticals in water: Development of a new approach based on magnetic sector mass spectrometry and application in the Nairobi River basin, Kenya, Sci. Tot. Environment, 437, 153-164.

Kostopoulou, M., and Nikolaou, A. (2008) Analytical problems and the need for sample preparation in the determination of pharmaceuticals and their metabolites in aqueous environmental matrices, Trends in Analytical Chemistry, 27(11), 1023-1035.

Lin WC, Chen HC, Ding WH (2005) Determination of pharmaceutical residues in waters by solid-phase extraction and large-volume on-line derivatization with gas chromatography-mass spectrometry, $J$ Chromatogr A, 1065, 279-285.

Lin Y-C., Lin C.A, Tung HH, Char NS (2010) Attenuation of Acetaminophen, Caffeine, Propranolol and Acebutolol in Aqueous Environments: Potential for Biodegradation and Sorption, $J$ Hazard Mater, $183,242-250$.

Madureira T., Barreiro J., Rocha M., Cass Q., Tiritan M, (2010) Spatiotemporal distribution of pharmaceuticals in the Douro River estuary (Portugal), Sci. Tot. Environment, 408(22), 5513-5520.

Moldovan (2006) Occurrences of pharmaceutical and personal care products as micropollutants in rivers from Romania, Chemosphere, 64, 1808-1817.

Munoz, F., and von Sonntag, C. (2000) The reactions of ozone with tertiary amines including the complexing agents nitrilotriacetic acid, Chem Soc Perkin Trans, 2, 2029-2037.

Nikolai, L.N., McClure, E.L., MacLeod, S.L., Wong, C.S. (2006) Stereoisomer quantification of the $\beta$ blocker drugs atenolol, metoprolol, and propranolol in wastewaters by chiral high performance liquid chromatography-tandem mass spectrometry, J Chromatogr A, 1131, 103-109.

Nikolaou A., Meric S., Fatta D. (2007) Occurrence patterns of pharmaceuticals in water and wastewater environments, Analytical and bioanalytical chemistry, 387(4),1225-34.

O'Connor, S., Aga, D.S. (2007) Analysis of tetracycline antibiotics in soil: Advances in extraction, cleanup, and quantification, Trends Anal Chem, 26, 456-465.

Ouyang G, Pawliszyn J (2006) SPME in environmental analysis, Analytical and Bioanalytical Chemistry, 386(4), 1618-2642.

Perez, S., Barcelo, D. (2007) Application of advanced MS techniques to analysis and identification of human and microbial metabolites of pharmaceuticals in the aquatic environment, Trends Anal Chem., 26, 494-514.

Petreas M., Park J.S., Wang M., Wang Y., Guo W., Tarrant A., Rhee A., Harwani S. (2012) The California Biomonitoring Program: persistent organic pollutants in archived and contemporary serum, Global NEST Journal, 14(1) 80-85.

Petrovic M, Gonzalez S, Barcelo D (2003) Analysis and removal of emerging contaminants in wastewater and drinking water, Trends Anal Chem, 22, 685-696.

Petrovic, M., Gros, M., Barcelo, D. (2006) Multi-residue analysis of pharmaceuticals in wastewater by ultra-performance liquid chromatography -quadrupole-time-of-flight-mass spectrometry, J Chromatogr A, 1124, 68-81. 
Quintana JB, Reemtsma T (2004) Sensitive determination of acidic drugs and triclosan in surface and wastewater by ion-pair reverse-phase liguid chromatography/tandem mass spectrometry, Rapid Commun Mass Spectrom, 18, 765-774.

Rodil R., Quintana J.B., Cela R. (2012) Transformation of phenazone-type drugs during chlorination, Water Res, 46(7), 2457-2468.

Rodriguez I, Quintana JB, Carpinteiro J, Carro AM, Lorenzo RA, Cela R (2003) Determination of acidic drugs in sewage water by gas chromatography-mass spectrometry as tert.-butyldimethylsilyl derivatives, J Chromatogr A, 985, 265-274.

Santos, F.J., Galceran, M.T. (2002) The application of gas chromatography to environmental analysis, Trends Anal Chem, 21, 672-685.

Seitz, W., Schulz, W., Weber, W.H. (2006) Novel applications of highly sensitive liquid chromatography/mass spectrometry/mass spectrometry for the direct detection of ultra-trace levels of contaminants in water, Rapid Commun Mass Spectrom, 20, 2281-2285.

Siddique A., Saied S., Alam Zaigham N., Mumtaz M., Ali Mahar G., Mohiuddin S. (2012) Temporal variability of disinfection by-products concentration in urban public water system, Global NEST Journal, 14(4), 393-398.

Smeti E., Samios S., Nikolaou A., Golfinopoulos S., Lekkas T.D. (2011) Statistical analysis of trihalomethanes in treated-water tanks: seasonality, local variability and correlations, Global Nest Journal, 13(1), 41-49.

Snyder, S.A., Wert, E.C., Rexing, D.J., Zegers, R.E., Drury, D.D. (2006) Ozone oxidation of endocrine disruptors and pharmaceuticals in surface water, Ozone Sci Eng, 28, 445-453.

Stolker, A.A.M., Niesing, W., Hogendoorn, E.A., Versteegh, J.F.M., Fuchs, R., Brinkman, U.A.T. (2004) Liquid chromatography with triple-quadrupole or quadrupole-time of flight mass spectrometry for screening and confirmation of residues of pharmaceuticals in water, Anal Bioanal Chem, 378(9), 955-963.

Stuber, M., Reemtsma, T. (2004) Evaluation of three calibration methods to compensate matrix effects in environmental analysis with LC-ESI-MS, Anal Bioanal Chem, 378, 910-918.

Stumpf M, Ternes T, Wilken R, Rodrigues S, Baumann W (1999) Polar drug residues in sewage and natural waters in the state of Rio de Janeiro, Brazil. Sci Total Environ, 225, 135-141.

Thaker (2005) Pharmaceutical data elude researchers, Environ Sci Technol, 139,193-194A.

Thomaidis N.S., Asimakopoulos A.G., Bletsou A.A. (2012) Emerging contaminants: a tutorial mini-review, Global NEST Journal, 14(1) 72-79.

Valcárcel Y., Alonso S.G., Rodríguez-Gil J.L., Maroto R.R., Gil A., Catalá M. (2011) Analysis of the presence of cardiovascular and analgesic/anti-inflammatory/antipyretic pharmaceuticals in river- and drinking-water of the Madrid Region in Spain, Chemosphere, 82(7), 1062-1071.

Van De Steene JC, Mortier KA, Lambert WE (2006), Tackling matrix effects during development of a liquid chromatographic-electrospray ionisation tandem mass spectrometric analysis of nine basic pharmaceuticals in aqueous environmental samples, $J$ Chromatogr, 1123, 71-81

Vogna, D., Marotta, R., Napolitano, A., Andreozzi, R., d'Ischia, M. (2004) Advanced Oxidation of the Pharmaceutical Drug Diclofenac with UV/H2O2 and Ozone, Water Res, 38(2), 414-422.

Vogna, D., Marotta, R., Napolitano, A., d'Ischia, M. (2002) UV/H2O2-Induced Hydroxylation/Degradation Pathways and $15 \mathrm{~N}$-aided Inventory of Nitrogenous Breakdown Products, J Org Chem, 67(17), 61436151.

Weigel, S., Berger, U., Jensen, E., Kallenborn, R., Thoresen, H., Huhnerfuss, H. (2004) Determination of selected pharmaceuticals and caffeine in sewage and seawater from Tromsø/Norway with emphasis on ibuprofen and its metabolites, Chemosphere, 56, 583-592.

Wiegel S., Aulinger A., Brockmeyer R., Harms H., Loffler J., Reincke H., Schmidt R., Stachel B., Von Tumpling W., Wanke A (2004) Pharmaceuticals in the River Elbe and Its Tributaries, Chemosphere, 57, 107-126.

Zhao J.L., Ying G.G., Wang L., Yang J.F., Yang X.B., Yang L.H., Li X. (2009) Determination of phenolic endocrine disrupting chemicals and acidic pharmaceuticals in surface water of the Pearl Rivers in South China by gas chromatography-negative chemical ionization-mass spectrometry, Sci. Tot. Environment, 407(2), 962-974. 